\title{
Objeto de aprendizagem digital para auxiliar o processo de ensino-aprendizagem no Ensino Técnico em Informática
}

\author{
Lisandro Lemos Machado* \\ Juliano Tonezer da Silva**
}

Resumo. O presente trabalho tem como finalidade realizar um estudo sobre objetos de aprendizagem digitais, que são módulos de informação autônomos, utilizados para auxiliar e dinamizar o processo de ensino-aprendizagem, atuando como recursos interativos. Realizou-se, em primeiro lugar, uma análise de sua definição e de suas principais características, buscando-se destacar seus pontos mais relevantes. Posteriormente, foi desenvolvido um módulo sobre montagem de computadores, destinado ao auxílio das aulas de um Curso de Ensino Técnico em Informática, a fim de colocar em prática os resultados obtidos. Por fim, procedeu-se a uma análise de sua aplicação, obtendo-se algumas conclusões a respeito de sua utilização como material de apoio ao ensino.

Palavras-Chave: Objetos de aprendizagem. Interação. Ensino técnico.

\section{Digital learning object to assist the teaching-learning process at}

\section{a technical course on computer sciences}

\begin{abstract}
The objective of this work is to carry out a study about digital learning objects, which are automated information modules, used to assist and accelerate the teaching-learning process, working as interactive resources. At first, an analysis of the definitions and main characteristics of those learning objects was made, trying to highlight its more relevant points. Based on this analysis, one module about assembly of computers was developed, in order to assist classes at a Technical Course on Computer Sciences, to put into practice the results achieved. Finally, an analysis of the use of that module was performed, leading to conclusions about the use of the module developed to assist the teaching.
\end{abstract}

Keywords: learning objects. Interaction. Technical Course.

\section{Introdução}

O avanço das tecnologias de comunicação, mais precisamente a popularização dos computadores e da internet, tornou-se tão presente na vida cotidiana, que torna-se

\footnotetext{
" Professor do Curso Técnico em Informática da Escola Estadual de Educação Profissional João de Césaro; pósgraduando em Informática Aplicada à Educação pela Universidade de Passo Fundo; lisandrolm@terra.com.br.

" Professor orientador, doutorando em Informática na Educação e mestre em Ciência da Computação pela Universidade Federal do Rio Grande do Sul; professor do curso de Ciência da Computação da Universidade de Passo Fundo; tonezer@upf.br. V.3 $\mathrm{N}^{\circ}$ 2, Novembro, 2005
} 
impossível ignorá-lo, tanto que a sociedade moderna já é denominada por muitos de "sociedade da informação e comunicação". Como Teixeira define:

O papel de destaque das novas tecnologias de informação na sociedade atual

é atribuído à valorização da informação. Assim, tudo aquilo que potencialize o seu manuseio representa um elemento importante nesse processo, no qual a informação emerge como matéria-prima e a tecnologia, como um meio de agir sobre ela. Nesse sentido, podem-se apontar tais tecnologias como as principais propulsoras e mantenedoras da atual sociedade. (2002, p. 25)

Nesse contexto, a área da Educação vem buscando, juntamente com a da Informática, propor uma melhoria no processo educacional, através do uso de ferramentas digitais. Uma das pesquisas mais atuais para a criação dessas ferramentas, são os objetos de aprendizagem, que visam proporcionar uma maior interatividade na forma de transmissão de conteúdos.

Propôs-se, então, o estudo sobre o assunto, para analisar se essa seria uma ferramenta adequada para proporcionar aos alunos de Ensino Técnico em Informática uma habilidade prática, característica essencial a ser desenvolvida por eles.

\section{Objetos de Aprendizagem}

Objetos de aprendizagem são conceituados como segmentos de informação autônoma, ou seja, módulos de conteúdo, onde cada um apresenta recursos específicos de ensino, que podem ser utilizados tanto individualmente, quanto em conjunto com outros, e são "designados e/ou utilizados para propósitos instrucionais" (Bettio e Martins apud Muzio, 2001). Eles podem ser tanto digitais quanto não-digitais, mas a ênfase, nessa pesquisa, foi dada aos primeiros.

Um objeto de aprendizagem tem como função atuar como recurso didático interativo, abrangendo um determinado segmento de uma disciplina e agrupando diversos tipos de dados como imagens, textos, áudios, vídeos, exercícios, e tudo o que pode auxiliar o processo de aprendizagem. Pode ser utilizado - tanto no ambiente de aula, quanto na Educação à Distância - como complemento, revisão ou reforço de um determinado conteúdo já estudado. Como afirmam Bettio e Martins (2004), eles "vêm para facilitar e melhorar a qualidade do ensino, proporcionando aos tutores, alunos e administradores, diversas ferramentas facilitadoras".

Para complementar e ressaltar a importância educacional, convém, ainda, citar Filho e Machado (2004), quando afirmam que "o objeto de aprendizagem tem a propriedade de, quando manipulado dentro de um contexto de busca de conhecimento, servir de mediação e facilitação para a formação e consolidação de um saber novo".

Pode-se utilizar um objeto de aprendizagem, por exemplo, para realizar simulações de experiências e atividades práticas. Ele permite que o aluno teste, de maneira prática e interativa, inúmeras possibilidades do exercício proposto, que, se tivesse sido estudado apenas teoricamente, não estimularia tanto a aprendizagem do conteúdo. A utilização de um objeto de aprendizagem não deverá ser desvinculada de um contexto, como defendem Nascimento e Morgado (2000) quando destacam que "Os professores desempenham papéis importantes na implementação de tecnologia nas salas de aula. Eles decidem sobre "como, quando, e como usar" a tecnologia em sala".

As seguintes características dos objetos de aprendizagem são apontadas por Silva (2004): autonomia: capacidade de serem utilizados individualmente, desvinculados de outros; interatividade: apresentação do conteúdo de forma dinâmica, permitindo a interação; reutilização em diversos contextos e propósitos: possibilidade de serem utilizados tanto para seu contexto inicial quanto reutilizados em outras áreas de ensino; agrupamento em conjuntos maiores: agrupamento de diversos módulos de conteúdos específicos, de maneira a garantir um ambiente de aprendizado mais rico e flexível.

Como complementação desse conjunto, podem ser acrescentadas as seguintes características, levantadas por Bettio e Martins (2004), citando Longmire (2004): 
flexibilidade: caracteriza-se pela permissão da criação de novos cursos utilizando-se conhecimentos já escritos e consolidados. Isso garante que o uso da tecnologia tenha uma maior credibilidade, pois eles se sustentam por fontes seguras de informação; customização: possibilidade de que cada entidade educacional os utilize e arranje da maneira que melhor lhe convier e de que as pessoas possam montar seus próprios conteúdos programáticos, agrupando os módulos conforme seu interesse (on-demand learning); interoperabilidade: consiste na utilização e reutilização dos objetos de aprendizagem em qualquer plataforma de ensino em todo o mundo, pois eles serão desenvolvidos de tal forma que possam ser utilizados em diversos sistemas; indexação e procura: caracteriza a padronização dos objetos de aprendizagem e dos locais onde eles são armazenados, para que a localização de um conteúdo se torne mais viável.

Além das anteriores, outras características acerca dos objetos de aprendizagem, verificadas por Silva, são de grande relevância. A primeira delas é a utilização de repositórios, com o intuito de armazená-los. Eles são conceituados como locais específicos onde os objetos de aprendizagem são disponibilizados, facilitando, assim, o a localização dos módulos. A segunda é a identificação por metadados, que funcionam "como "etiquetas" identificadoras de seu conteúdo, que descrevem como, onde e por quem foram desenvolvidos, para que segmento é destinado, seu tamanho, aplicação e outras informações que se fizerem relevantes" Silva (2004).

A importância da classificação de metadados e do armazenamento dos objetos de aprendizagem em "um repositório integrável a um sistema de gerenciamento de aprendizagem" também é ressaltada por Tarouco et al. (2003). Igualmente, a autora também ressalta a estratégia de se adotar padrões abertos com o objetivo de tornar os objetos independentes de plataforma possibilitando seu uso em "diferentes sistemas operacionais e plataformas de hardware". Esse fator é extremamente importante devido à rapidez dos avanços tecnológicos, onde, enquanto novos ambientes surgem, outros caem em desuso, dessa forma, o fato de os módulos serem construídos livres de ambientes, proporciona um maior tempo de vida à esses recursos.

Através do estudo dessas características, julgou-se poder utilizar os objetos de aprendizagem para padronizar os materiais educacionais. Essa adoção de padrões é de grande importância, pois garante que os módulos individuais possam ser agrupados de diversas maneiras e utilizados em conjunto, com garantia de que os mesmos seguirão as mesmas normas de desenvolvimento.

A aprendizagem sob demanda é outro fator considerado impactante por Silva. O

aluno pode, ao se habituar à utilização de objetos, gerenciar sua própria aprendizagem,

fazendo uso das informações na hora, lugar e situação que julgar mais apropriadas. A informação será específica para cada situação, e a aprendizagem poderá ser feita ao longo da vida.

Baseando-se em todas as funcionalidades dos objetos de aprendizagem averiguadas, considera-se que a utilização dos mesmos nos processos de ensinoaprendizagem pode trazer grandes mudanças à educação. Então, ao final desse estudo teórico, julgou-se importante colocar em prática algumas de suas características, através 
do desenvolvimento de um módulo, para que se proceda a uma análise dos resultados de sua aplicação.

\section{Objeto de aprendizagem sobre montagem de computadores}

Após o estudo teórico, buscou-se colocar em prática o maior número possível das características atribuídas aos objetos de aprendizagem e analisar seu resultado, através do desenvolvimento de um módulo de conteúdo denominado "Introdução à montagem de computadores", com o objetivo de ser aplicado como complemento de estudos em um Curso Técnico em Informática.

O público-alvo foi escolhido por se tratar de um grupo de futuros profissionais da área da informática, que devem ter conhecimento prático sobre o assunto em questão, mas que não possuem equipamentos atualizados para aprender a montar um computador. O objetivo do desenvolvimento do módulo foi proporcionar a interatividade necessária a uma aprendizagem sempre atualizada, sem requerer do estabelecimento de ensino gastos altíssimos com equipamentos, e, ao mesmo tempo, não prejudicando o aluno na prática futura de sua profissão.

O conteúdo escolhido abrange um assunto de extrema importância dentro do referido curso, uma vez que garante o primeiro contato didático do aluno com a montagem de um computador. O módulo foi desenvolvido com o objetivo de auxiliar os professores na transmissão dos conceitos iniciais de montagem de computadores, permitindo que o aluno, após o estudo teórico, tivesse a possibilidade de testar as conexões básicas a serem realizadas nesse processo.

\subsection{Tecnologias para o desenvolvimento}

Um item de grande relevância no desenvolvimento de objetos de aprendizagem é a utilização de recursos multimídia - através de múltiplas formas de mídia (textos, sons, 
imagens, animações, entre outros), transmitem uma mensagem, idéia ou pensamento que necessitem da utilização dos mais diversos sentidos -, como auxiliares na geração da interatividade. Foi dada a ênfase, no módulo desenvolvido, aos visuais, uma vez que o objetivo é a recriação de uma experiência prática que utiliza basicamente o sentido da visão.

Após a análise e da verificação das necessidades do objeto a ser desenvolvido, julgou-se que o software "Macromedia Flash ${ }^{\circledR}$ " (versão trial) foi o mais adequado para atuar como plataforma de desenvolvimento, visto que a riqueza de possibilidades de produção que são oferecidas possibilita a criação de interatividade e de um resultado final bastante atrativo. Um aspecto que torna o Flash uma ferramenta de desenvolvimento adequada é a criação de animações e a utilização de imagem vetorial como seu modo padrão, para o trabalho com imagens gráficas. Conforme afirmam Franklin e Brooks (2000), "Essa é uma forma eficiente de tratar imagens gráficas e freqüentemente resulta em tamanhos de arquivo relativamente pequenos".

Devido ao flash utilizar seu próprio plug-in, existente para os mais diversos sistemas operacionais, uma das características dos objetos de aprendizagem que pode ser contemplada através dessa ferramenta, é a padronização dos recursos digitais. Ela é extremamente importante, para que não haja a incompatibilidade entre o objeto desenvolvido e os navegadores ou sistemas operacionais onde o mesmo será utilizado.

Para a criação das imagens, optou-se por utilizar o software Corel Draw ${ }^{\circledR}$ (versão trial) - um programa profissional de desenho que também baseia-se em vetores para a construção das figuras. Ele permite que se possa manter grande semelhança das figuras desenvolvidas com imagens reais. Garante-se, assim, que os desenhos do módulo possuam detalhismo a ponto de possuírem grande semelhança com um computador real. 


\subsection{Desenvolvimento do objeto de aprendizagem}

Escolhidas as tecnologias de desenvolvimento, o passo seguinte foi iniciar o processo de criação, através da problematização do tema escolhido. Para que os alunos fossem motivados a realizar as atividades do módulo, eles foram levados a surpreenderem-se pela situação de encontrar um dos computadores de sua empresa parcialmente desmontado. Dessa forma, pretendeu-se estimulá-los a buscar a resolução do referido problema, característica que é indispensável a um profissional da área da informática.

Após a tela de boas-vindas, que apresenta o título do módulo (Introdução à montagem de computadores), é apresentada a situação-problema, que deve ser solucionada pelo aluno. Em primeiro lugar, o computador aparece montado, representando a situação de um dia normal de trabalho do futuro técnico em informática.

$\mathrm{Na}$ tela seguinte, está representada a forma com que o técnico encontrou o computador ao chegar no trabalho, onde os componentes foram apresentados separadamente um do outro. O aluno é, então, incentivado a solucionar o problema que está à sua frente, sendo convidado a reconectar os componentes em seu devido lugar. Há, para isso, um botão para as figuras de cada uma das peças, com link para a tela de resolução da montagem daquele componente específico.

O aluno pode, a partir de qualquer das peças expostas na tela inicial, começar o seu trabalho, escolhendo a ordem na qual preferia iniciar a remontagem do computador (contemplando, assim, o aspecto de não-linearidade, que é de grande importância em ferramentas digitais interativas).

Para cada peça do computador, foi atribuída uma letra correspondente. As letras, em conjunto, formam códigos específicos, para identificar a conexão que foi realizada 
(por exemplo: a conexão D-G representa o encaixe da placa-mãe, através do cabo flat, ao disco rígido). Essa identificação permite que as mesmas possam ser anotadas, e posteriormente, utilizadas pelo professor em sala de aula.

O aluno poderá iniciar seu trabalho clicando em um dos componentes da tela. Ao escolher um deles, ele seguirá para uma nova tela, onde é apresentada a peça escolhida, na parte superior, e relacionados os demais elementos do computador, na parte inferior. Ele poderá escolher, dentre esses, qual ele julga ser o mais adequado para formar uma conexão com a peça em questão.

Após a conexão realizada, surge um questionamento ao aluno a respeito do motivo de ele considerar que ela é correta. O seu objetivo é fazer com que haja uma reflexão sobre a sua decisão, não fornecendo respostas prontas, requerendo a percepção do aluno, onde cabe a ele, chegar à conclusão, podendo verificar, por si próprio, a conseqüência e a validade de suas ações.

Independentemente do tipo apresentado, aparecerão todas as conexões possíveis entre aqueles componentes, permitindo, assim, que o aluno possa fazer todas as tentativas que julgar necessárias. O objeto foi construído com o intuito de possibilitar ao usuário a experimentação e avaliação das diferentes possibilidades de encaixe entre os componentes, podendo chegar, por si próprio, às conclusões a respeito de qual é a combinação ideal.

Em todas as telas, existe um botão que permite ao aluno retornar à tela principal, possibilitando que ele escolha qual o próximo componente que deseja conectar. Em algumas telas específicas, ainda, há a presença de dicas, visando auxiliar o aluno durante a realização da atividade, orientando-o a respeito de detalhes que devem ser observados no momento da escolha, para que a conexão escolhida por ele seja a correta.

Após a realização da conexão, aparece uma tela onde é demonstrado o encaixe selecionado sendo realizado, através de uma animação, simulando sua realização 
exatamente como em um computador real com a intenção de tornar o processo o mais verdadeiro possível.

Se o aluno constatar que a tentativa que realizou não foi a correta, existe um botão "Refazer" presente em todas as telas de conexão que permite retornar a tela anterior, propiciando que ele realize uma nova tentativa. Através desse procedimento, ele poderá testar todas as possibilidades de encaixe existentes, assim como em um procedimento de montagem real, e analisar todas as situações ocorridas, tendo a possibilidade de concluir qual foi a melhor. Caso deseje sair da tela de conexão da peça em questão, é disponibilizado um botão "Próximo", que permite que ele retorne à tela principal, onde pode escolher uma outra peça para conectar.

Assim que ele realizar uma conexão que julgue a correta, deve proceder à anotação do código de conexão e da resposta para o questionamento. Assim, o professor poderá coletar e ter acesso aos resultados obtidos pelos alunos. De posse das respostas, pode-se certificar se eles têm uma justificativa para sustentar a sua decisão. Também há a possibilidade de se realizar uma análise e posterior discussão com os mesmos sobre os resultados obtidos, proporcionando, assim, um momento de reflexão em conjunto, onde possíveis dúvidas que surgirem ou, até mesmo, detalhes não percebidos anteriormente possam ser elucidados.

O objeto de aprendizagem desenvolvido buscou possibilitar ao aluno a visualização do resultado de sua ação, procurando oferecer a sensação de que ele está, realmente, manipulando peças reais, possuindo um controle da situação de montagem, definindo a ordem na qual o utilizará, realizando as operações de acordo com a sua própria vontade. Procurou-se, ainda, construir um recurso educacional diferente de outros existentes, como os livros didáticos ou os livros digitais - onde o aluno é um mero receptor de conteúdo, sem a menor oportunidade de escolher o que deseja visualizar-, sendo um ambiente que, devido a sua forma intuitiva de funcionamento, garantisse a fácil utilização e assimilação, oportunizando que o aluno dedicasse todo o 8 
tempo disponibilizado às experimentações, sem a necessidade de descobrir, previamente, como utilizá-lo.

Dessa forma, buscou-se oferecer condições para que o aluno pudesse testar e praticar conceitos aprendidos na teoria, de forma atualizada, mas sem o risco de danos a equipamentos, tendo a possibilidade de analisar as alternativas existentes e, através de seus erros e acertos, construir seus próprios conceitos.

\section{Utilização e avaliação do objeto de aprendizagem}

A fim de verificar se os objetivos pretendidos quando do desenvolvimento do objeto de aprendizagem foram alcançados, partiu-se para a sua utilização por um grupo de alunos de um curso Técnico em Informática.

$\mathrm{O}$ objeto foi aplicado em uma turma de iniciantes e uma mais avançada. $\mathrm{O}$ objetivo, ao realizar o processo dessa forma, foi analisar a atuação do módulo frente a diferentes níveis de conhecimento.

A fim de coletar os resultados obtidos durante a aplicação, para posterior análise, foi elaborada uma folha de respostas para servir como meio de obtenção e registro das respostas dos alunos, durante o processo. Em um primeiro momento, os alunos tiveram de realizar anotações em relação às conexões das peças do computador, sendo que, para cada componente conectado, deveria ser registrado o código de identificação da conexão que ele julgou ser a correta e a resposta à questão "Por que você considera que este é o local correto?", para apurar o motivo que levou o aluno a considerar que o local onde foi realizada a conexão é o correto. Na segunda parte, eles responderam questões relacionadas ao objeto de aprendizagem, onde procuraram avaliá-lo em relação à contribuição para a aquisição de novos conhecimentos, a facilidade de utilização sob o aspecto da organização do conteúdo e da navegação, se era uma ferramenta que possibilitaria uma melhor compreensão do conteúdo, devido à interação propiciada pelo 
mesmo e, por último, o que o aluno achou de poder escolher a ordem de montagem das peças sem ser forçado a seguir uma ordem pré-determinada. Ainda na folha de respostas foi possibilitado um espaço para que os alunos escrevessem livremente sua opinião sobre o módulo que acabaram de utilizar.

\subsection{Metodologia de utilização do objeto de aprendizagem}

$\mathrm{Na}$ aplicação do objeto de aprendizagem "Introdução à montagem de computadores", os alunos puderam utiliza-lo durante dois períodos (duas horas).

Durante a aplicação, os alunos foram deixados à vontade para utilizar a ferramenta livremente, evitando-se, para isso, a intervenção na forma como eles a utilizariam, participando-se apenas quando houve solicitação. Procurou-se, então, observar as suas reações, a forma como navegavam e a seqüência de passos que foram seguidos. O que se pôde perceber foi que, em momento algum, os alunos demonstraram dificuldade de navegação ou confusão em relação ao que deveria ser realizado.

Através da observação da aplicação, juntamente aos alunos, apurou-se que o módulo despertou seu interesse, não apresentando complexidade, nem provocando momentos de incompreensão, podendo-se julgar que ele atingiu o objetivo de ser intuitivo, sendo de simples utilização e assimilação.

\subsection{Organização e análise dos resultados}

A fim de obter um resultado mais concreto dos alunos, quando da utilização do módulo, utilizou-se a folha de respostas (descrita no início desta seção), para que eles procedessem às anotações, conforme utilizavam o objeto, emitindo, inclusive, suas opiniões sobre pontos questionados.

Para interpretar o conteúdo das folhas de resposta, foi feita uma análise qualitativa sobre os resultados. Ela ocorreu através da criação de categorias para cada peça com base nas respostas obtidas, seguindo a definição de Gomes (1993, p. 70): “As 10 
categorias são empregadas para se estabelecer classificações. Nesse sentido, trabalhar com elas significa agrupar elementos, idéias ou expressões em torno de um conceito capaz de abranger tudo isso".

Para a realização desse processo, foram seguidas as três fases que Gomes (1993) aponta como integrantes da análise de conteúdos. A primeira diz respeito à organização dos dados que serão analisados, fase na qual ocorreu a leitura do material, e onde foram feitos os primeiros registros, buscando-se padrões entre as respostas obtidas para que se pudesse definir as categorias a serem utilizadas na classificação dos resultados. A segunda fase envolveu, novamente, a leitura de todo material, por diversas vezes, para que se pudessem enquadrar as respostas dentro das categorias criadas. A última fase foi referente à coleta das informações estatísticas, onde, após as anteriores, foi realizada a distribuição das respostas nas categorias, com o objetivo de quantificar cada uma delas, anotando-se, também, as justificativas que não fossem abrangidas pelas categorias.

As bases para a criação das categorias de classificação das respostas foram as características dos componentes em conjunto com as justificativas dos alunos. Para cada um deles foi criada uma lista de categorias resultante de sua intersecção com as respostas. Algumas peças, por possuírem características semelhantes, receberam categorias iguais, pois as respostas puderam ser agrupadas da mesma maneira.

Depois de classificadas todas as respostas, os resultados obtidos foram comparados com o código de encaixe das peças, para realizar a apuração de quais foram as corretas. Feito isso, procurou-se analisar as categorias para encontrar quais foram os fundamentos utilizados pelos alunos. Através desse passo, pôde-se concluir que eles se basearam com freqüência em aspectos como cor e forma dos conectores, encaixe das peças (visualizado através do módulo), e conhecimentos próprios (consequiência de experiências anteriores na montagem de computadores). 
Contabilizados todos os resultados, pôde-se constatar que os resultados obtidos pelas duas turmas que utilizaram o módulo foram semelhantes, e que, em um aspecto geral, os alunos não demonstraram dificuldades para realizar os encaixes corretos. As exceções ocorreram na conexão das caixas de som e do disco rígido, onde foi percebido que houve certa confusão entre os encaixes.

O resultado do processo de aplicação possibilitou analisar o relacionamento entre o estudante e o conteúdo. Através dele, pôde-se perceber onde estão os pontos em que os alunos apresentam mais dificuldades, apoiando o professor e oferecendo a oportunidade de corrigir eventuais problemas que possam vir a atrapalhar o andamento da disciplina e até mesmo a atividade profissional do futuro técnico.

Na segunda parte da folha de respostas, registrou-se a impressão dos alunos em relação a alguns aspectos do objeto de aprendizagem utilizado, conforme descrito no início da seção. Eles consideraram-lhe interessante para todos aqueles que não possuem prática na área e, também, julgaram-lhe capaz de auxiliar a aquisição de novas informações. Ressaltaram-se pontos como a facilidade de uso e a distribuição do conteúdo. Destacou-se a oportunidade de visualização da conexão, dinamizando o contato com a mesma e facilitando a compreensão da matéria e também o fato de não existir uma seqüência pré-determinada para realizar as conexões.

Puderam, também, ser coletadas as impressões obtidas sobre o objeto de aprendizagem. Foi considerado que ele é um método eficiente e útil de ensino, pelo uso da interatividade e pela fácil assimilação e manuseio, transformando-se, assim, em uma ótima ferramenta de aprendizagem para quem está iniciando, pois propicia uma facilidade de compreensão da montagem, mesmo sem haver contato físico com a máquina. Dessa forma, houve a possibilidade do teste dos encaixes, sem prejudicar componentes de hardware. Algumas opiniões, entretanto, apontaram a falta de uma tela indicando se a conexão realizada foi correta ou não. Isso demonstra que muitos alunos, 12 
devido ao hábito de sempre receberem respostas prontas, sentem falta disso, o que acaba fugindo da pretensão deste trabalho, que é justamente o oposto: fazer com que eles construam suas próprias respostas, estimulando-os, assim, a reflexão acerca da montagem.

Ao término da análise das avaliações e da observação da utilização do objeto de aprendizagem, foram criadas condições de avaliá-lo em sua atuação, podendo-se chegar a algumas considerações sobre sua utilização como um recurso didático.

\section{Considerações Finais}

Observou-se, através desse estudo, que os objetos de aprendizagem possuem um potencial de aperfeiçoar o processo educacional, pois são recursos interativos com características capazes de garantirem grandes benefícios para a educação, dinamizando a relação aluno-conteúdo, onde o primeiro não age apenas como um mero expectador, mas, através do módulo, tem a possibilidade de construir seu conhecimento.

Tendo como base essa conclusão, foi desenvolvido um módulo utilizado como apoio às aulas de montagem e manutenção de computadores, de um curso Técnico em Informática, visando colocar em prática alguns dos conceitos estudados na fase de conceitualização, para avaliar os mesmos em situações concretas de uso.

A aplicação do módulo, e a observação desse processo, proporcionaram materiais para que se pudesse avaliar o objeto de aprendizagem. Os dados obtidos foram muito satisfatórios, não sendo constatada nenhuma dificuldade de navegação e compreensão em relação ao conteúdo, atingindo-se os objetivos: facilidade de uso e navegação intuitiva. As informações coletadas utilizando-se o questionário de avaliação oportunizaram visualizar as conexões realizadas pelos estudantes e o porquê delas, bem como suas impressões sobre o módulo. Pôde-se constatar, dessa forma, quais 
componentes que originaram maiores dificuldades no ato da montagem, possibilitando, assim, que o professor tivesse mais uma forma de identificar desvios na aprendizagem.

Após o processo de avaliação, concluiu-se que os objetivos pretendidos na construção do objeto de aprendizagem foram atingidos, em sua grande maioria. Considera-se que, futuramente, poderá ser adicionada a ele uma série de funcionalidades, com vistas ao seu melhoramento, como, por exemplo, a possibilidade de armazenar as conexões realizadas e, após o aluno ter realizado todos os encaixes, apresentar uma tela final, com o resultado da montagem que ele executou, oferecendo a possibilidade de se testar o computador montado. Há a possibilidade de que, em estudos futuros, sejam desenvolvidos outros módulos, abordando assuntos mais específicos dos que foram apresentados neste. Sendo assim, outros objetos de aprendizagem relacionados ao funcionamento da máquina poderão ser desenvolvidos, abordando, de maneira individual, outros componentes, como a placa-mãe, o disco rígido, o monitor, entre outros.

Existe, ainda, a possibilidade de realizar a associação dos conteúdos trabalhados com outras áreas do conhecimento. Isso pode ocorrer através da criação de novos módulos, sobre assuntos interligados ao objeto desenvolvido. Por exemplo, a partir da ligação do computador com a energia elétrica, através do estabilizador, pode-se desenvolver uma proposta de estudo sobre eletricidade, ou então, do magnetismo como forma de gravação no disco rígido e discos flexíveis. Esses novos módulos, então, poderiam ser utilizados em aulas de física, ou, ainda, de disciplinas específicas de Cursos Técnicos em Eletrônica, promovendo, a interdisciplinaridade.

Considerou-se, através desse estudo, que, não apenas na teoria, os objetos de aprendizagem têm o potencial de revolucionar a educação. Acredita-se que sua utilização, de maneira completa, no processo educacional, pode preencher lacunas deixadas pela educação tradicional, que, em sua grande parte, enfatiza apenas a teoria. 14 V. $3 \mathrm{~N}^{\circ} 2$, Novembro, 2005 
A utilização desses recursos interativos no ensino técnico pode garantir uma melhora significativa da qualidade desses futuros técnicos no mercado de trabalho, ajudando a quebrar o preconceito de que apenas o ensino superior é capaz de formar profissionais qualificados.

\section{Referências bibliográficas}

BETTIO, Raphael Winckler de; MARTINS, Alejandro. Objetos de Aprendizagem - Um novo modelo direcionado ao Ensino a Distância. Disponível em: <http://www.universia.com.br/materia/materia.jsp?id=5938>. Acesso em : 15 mar 2005 .

FILHO, Clovis Soares e Sá; MACHADO, Elian de Castro. O computador como agente transformador da educação e o papel do objeto de aprendizagem. Disponível em: <http://www.universiabrasil.net/materia/materia.jsp?id=5939>. Acesso em : 25 set 2005 .

FRANKLIN, Derek; PATTON, Brooks. Flash 4! Animação criativa na web. São Paulo: Campus, 2000.

GOMES, Romeu. A análise de dados em pesquisa qualitativa. In. Pesquisa Social: teoria, método e criatividade, Organizado por Maria Cecília de Souza Minayo. Petrópolis: Vozes, 2004, p. 67-80.

NASCIMENTO, Anna C. ; MORGADO, Eduardo. Um projeto de colaboração Internacional na América Latina. <http://rived.proinfo.mec.gov.br/artigos/rived.pdf>. Acesso em : 10 mar 2005.

SILVA, Maria da Graça Moreira da. Novas Aprendizagens. Disponível em: <http://www.abed.org.br/congresso2004/por/htm/146-TC-D2.htm>. Acesso em: 10 mar 2005. 
TAROUCO, Liane Margarida Rockenbach; FABRE, Liane Margarida Rockenbach; TAMUSIUNAS, Fabrício Raupp. Reusabilidade de objetos educacionais. Disponível em: <http://www.cinted.ufrgs.br/renote/fev2003/artigos/marie_reusabilidade.pdf>. Acesso em: 25 set 2005.

TEIXEIRA, Adriano Canabarro. Internet e a democratização do conhecimento: repensando o processo de exclusão social. Passo Fundo: UPF, 2002. 